\title{
THE SELF-REPORTED CONFIDENCE AND PROFICIENCY LEVELS OF UNDERGRADUATE ENGINEERING STUDENTS IN AN ENGINEERING TECHNICAL COMMUNICATION COURSE
}

\author{
Anne Parker and Kathryn Marcynuk \\ Centre for Engineering Professional Practice \& Engineering Education \\ University of Manitoba \\ Anne.Parker@umanitoba.ca; ummarcyk@cc.umanitoba.ca
}

\begin{abstract}
We have conducted surveys at the beginning and the end of semesters in an Engineering Technical Communication course, surveys that are designed to determine how confident our students feel about "Communication Skills" and personal skills development, or "Lifelong Learning" (defined here as the ability to devise ways to develop broader knowledge and to identify personal strengths and weaknesses). Our objective is to see whether students' confidence levels increase and then compare these levels with where students believe they should be once they graduate. In this paper, we report on the data obtained from these two surveys conducted from Winter 2013 until Winter 2015. Normally, one section of the class completed the surveys, although two sections (A01 and A02) completed the surveys in both the Winter 2013 semester and in the Winter 2015 semester, for a total of 9 classes that participated.. So far, we have found that students do indeed feel more confident in all the surveyed areas at the end of the semester.

Yet, regardless of their growing confidence, many students also feel they have not yet achieved the level of proficiency expected of them once they graduate. For example, for "personal skills" (such as applying critical inquiry and analysis to engineering problems and doing the communications that support the engineering work), 5 represents an ability to lead or innovate in a particular area, and 3 indicates an ability to understand and explain. In our surveys the aggregate was 3.4 for the initial survey ( $n=450$ students) and 3.5 for the end-of-term survey $(n=378)$. Most telling, however, is the level students feel they must achieve by the time they graduate (4.5). In other words, by acknowledging that lifelong learning is an important attribute, one that they will have to continue to develop if they are ever to achieve the level expected of them, students demonstrate a remarkable level of selfawareness.
\end{abstract}

Keywords: Communication skills, lifelong learning, confidence levels, undergraduate engineering education

\section{INTRODUCTION}

Our involvement in a Technical Communication course in a Faculty of Engineering for many years has given us some insight into how engineering students generally feel about writing. Mostly, these feelings are varying levels of discomfort - discomfort at the thought of having to do it and discomfort in actually doing it. On the whole, engineers feel a decided lack of confidence in their ability to communicate effectively, especially in writing. But anecdotal information, while interesting, doesn't always tell the whole story. Consequently, we designed two short surveys that will let students anonymously self-report on their levels of confidence in four critical areas - writing, speaking, teamwork and personal skills development, or lifelong learning. Additionally, on the second survey, we asked students to indicate the level of proficiency they believed would be expected of them once they graduated as engineers.

We administer the first survey at the beginning of a semester and the second at the end. Our goal was not to measure the effectiveness of the pedagogical approach taken in the course, nor was it our intent to measure a student's success in the course in terms of a grade achieved. Indeed, we have not yet addressed performance outcomes in terms of how effective our pedagogy has been, even though our students may well feel more confident because of the formative feedback and collaborative practice they receive or because of our encouraging reflective learning. To date, these outcomes are determined solely by the instructors' evaluation of student work, much like Paretti's practice [1].

Our reasons for doing so were straightforward. On one level, these were to be anonymous surveys where students would be able to answer the questions honestly, and without any link to grades and assessment or course outcomes. Therefore, we had no way of matching students to their survey responses or to their grades. On another level, in a communication class, grades by themselves cannot reflect a right or a wrong answer. Rather, a grade reflects the outcome of a process that develops over time and tends to be cumulative; much like a scaffold, each piece or step in the process is connected to the next so that, together, 
they form an identifiable structure or outcome. A grade, then, reflects an outcome only for that moment and only for that particular assignment. Additionally, communication skills are themselves cumulative, building one on the other - with practice and over time; as the process develops and progresses, the communicator gains confidence in his or her ability to communicate effectively.

\subsection{THE SURVEYS}

These surveys grew out of our curiosity about our students' levels of confidence in their communication skills, a general term that we used to encompass writing, speaking, teamwork and personal skills development (or lifelong learning), such as applying critical inquiry and analysis to engineering problems and to the communications that support the engineering work. Many of our students, like countless others in other engineering schools, come to technical communication with some trepidation since the subject, to them, is not particularly technical in scope nor is it "really" engineering. As such, it is usually the course they probably like the least and the one in which they may expect to do the worst. We suspected that, exacerbating this negativity, is their belief that, because this is the area where they are academically weaker, their confidence levels may be correspondingly weak. To date, there are few studies investigating how undergraduate engineering students estimate their confidence and proficiency levels in writing, speaking, teamwork and personal skills development, so we devised our own short survey that asked them how confident they felt in doing some of the basic communication tasks that we routinely ask them to do in the class and that they will be called on to do in their future careers as professional engineers.

On the first day of classes, after they have heard a brief introduction to the course itself as well as why communication is part of the engineering curriculum, we administer the first survey. The survey has a brief opening paragraph (that, incidentally, we do not even label as "directions"):

[Technical Communication] is a course that highlights the kinds of communication you will be doing as a professional engineer. Through practice, feedback, reflection and revision, the course is designed to help you become a better communicator. To that end, we would like to know how confident you are right now in doing the following (use the scale below as a guideline):

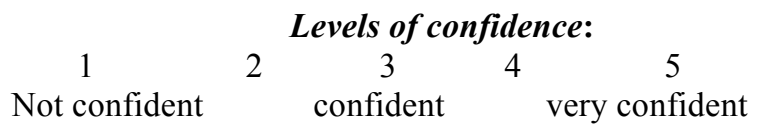

We ask them to use the scale for all 20 questions and for all four areas.

On the last day of classes, we administer the second survey, which asks them to respond to the same 20 questions, only now we ask them to indicate their "current level of proficiency" in completing a communication task. Much of the text remains the same, although now we have also added more disciplinespecific statements, such as the importance of communication to the profession, much like what Shoemaker did in her study [2]. Note as well that we ask them what they believe the expected proficiency level will be once they graduate.

[Technical Communication], as you know, is a course that highlights the kinds of communication you will be doing as a professional engineer. Because communication is so important to the profession - industry partners, for example, consider it to be one of the top three skills you will need - ENG 2010 helps you to become a more proficient communicator through practice, feedback, reflection and revision. When we started the term, we asked you about your levels of confidence on a number of related items. Now we would like to know, first, how proficient you are right now in doing the following (use the scales below as a guideline) and, secondly, how proficient you believe you will have to be when you graduate:

Levels of proficiency (based on CDIO levels, 2008):

1. to have experience or been exposed to

2. to be able to participate in and contribute to

3. to be able to understand and explain

4. to be skilled in the practice or implementation of

5. to be able to lead or innovate in

In the writing area, we ask them 5 questions related to document length, inclusion of graphics in their document, audience and the writer's engineering background. Here, we will focus on the responses to just two of these questions from each of the surveys. Question 1 asks how confident they are in writing shorter documents (less than 5 pages) that demand that you [the writer] have an engineering background (minimum of 1-2 years in an engineering program); this is usually the level of most of our students. Question 3 asks how confident they are in writing shorter 
documents for readers who do not have an engineering background. The results are shown below in Fig. 1 and Fig. 2.

"W" refers to the winter semester, "S" to the summer semester and "F" to the Fall semester; the blue bars show the results for Survey 1, students' current level of confidence, while the red bars show the results for Survey 2, what the students believe is their current level of proficiency.

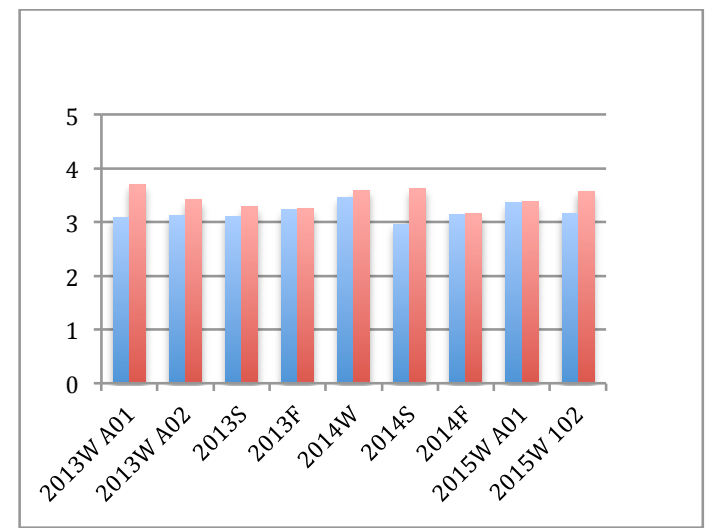

Fig.1. Q1: Writing a short document $(<5 \mathrm{pp}$.)

As shown in Fig. 1, students do indeed feel more confident, even though it is only marginally in some samples. On average, the change is +0.6239 points from the $1^{\text {st }}$ survey to the $2^{\text {nd }}$ survey. Interestingly, Question 3 shows a similar result for the most part, although the average change is lower $(+0.1676)$ and 3 sessions show a lower confidence level.

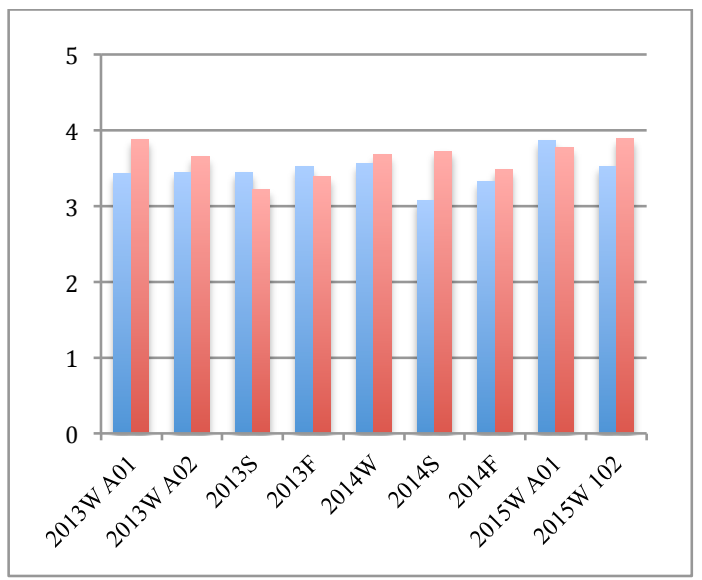

Fig. 2. Q3: Writing a short document for non-Engineering readers

In the personal skills, or lifelong learning, area, we ask them four questions related to identifying their own strengths and weaknesses, and applying critical inquiry and analysis to engineering problems and to the communications that support the engineering work. We will focus on two questions: Question 17, identifying personal strengths and weaknesses, and Question 19, working to develop broader knowledge. As shown below in Fig. 3, the average change for Question 17 is +0.1433 points, so their confidence levels are less marked in this area, though they still feel at least somewhat confident in their ability to identify their own strengths and weaknesses.

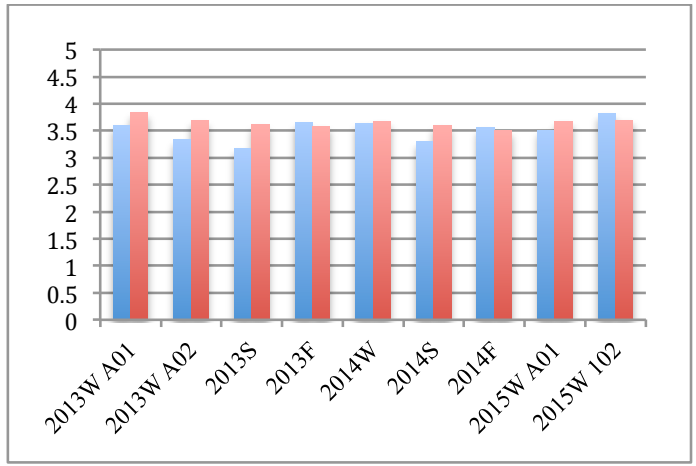

Fig. 3. Q17: Identifying your own areas of strength and weakness

However, when asked about their confidence levels in working to develop broader knowledge, student responses evince a marked decline in confidence; almost all the sessions feel less confident in this area than in any of the others. Here, the average change is -0.0552 points.

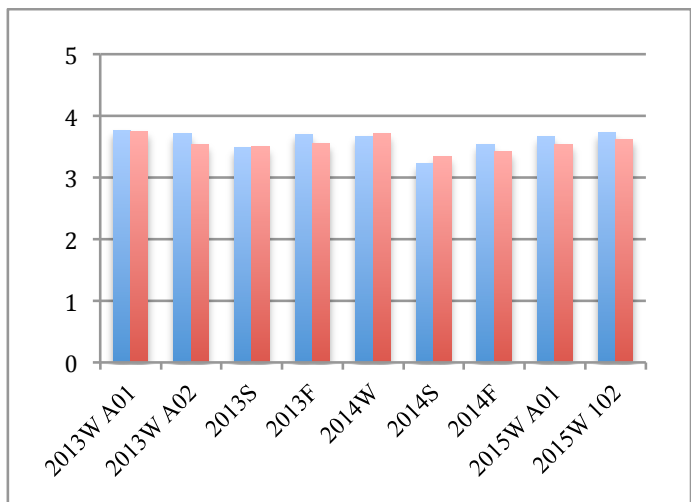

Fig. 4: Q19: Working to develop broader knowledge

There are likely many reasons to explain this decline, one of which is their having now finished the course and experienced first-hand the kinds of demands that will be placed on them as they move forward in their programs of study and, of course, once they graduate. Now that they've experienced the various communication genres and communication exigencies within a discipline-specific context, they may feel less well equipped to deal with these demands than they once did at the beginning of term - in other words, before they learned what it is that engineers do in terms of communication and lifelong learning. As well, they have now completed a major team-writing project that may 
have taught them how difficult being a professional can be in an increasingly complex learning and workplace environment, especially one where students believe the expected proficiency level is so high, as shown below:

\begin{tabular}{|c|c|}
\hline \multicolumn{2}{|c|}{ Expected Proficiency Level } \\
\hline Writing & Personal Skills \\
\hline Q1 -4.4 & Q17-4.5 \\
\hline Q3 -4.42 & Q19-4.49 \\
\hline
\end{tabular}

\subsection{CONCLUSION}

All in all, our students did gain a measure of academic confidence over the semester, and some studies would suggest that this growth in confidence does predict successful academic performance because a student's believing in his/her ability to do a task enhances that student's ability to successfully perform that task [4]. We've seen here that, after first hearing why they study technical communication in an engineering program, many students still display confidence in their abilities to do the necessary communication tasks. However, once they've experienced - first-hand - what it means to write a research-based team project, they may be less sanguine. Nevertheless, as Figures 1 and 2 show, they have attained a level of belief in their ability to do a set of communication tasks successfully.

However, in most engineering programs, often this cumulative process - of building upon the communication skills and the lifelong learning skills that have gone before - is interrupted. In large part, this is because few other courses include communication skills or lifelong learning in the teaching or in the assessment. Even when a technical course does include written assignments, for example, they are usually not graded for the quality of the writing but, rather, for the technical content [5].

Exacerbating this problem is yet another problem; that is, what do non-communication courses teach when it comes to communication skills? And are engineering professors prepared to do so anyway when they are primarily responsible for teaching the disciplinary content? Just as the engineering courses demand instructors who have what Pan and Timperley call considerable "content knowledge" in order to provide the kind of feedback required by the course [6], so, too, providing the formative feedback on written assignments requires a specialist with specialized knowledge. However, as Paretti points out, few engineering faculty members are trained in the finer points of providing communication feedback; they, like students, want to know the "how" when it comes to writing more than they worry about the "why" [1].
Sadly, communication is rarely mentioned as contributing to engineering success [7], probably because the technical work is often viewed, even now, as the "real work" [8].

Therefore, our challenge as engineering educators is to build on this momentum and help our engineering students to build the kind of academic confidence they will need to succeed on a myriad of levels, both academic and professional. As Paretti (who is herself an engineer as well as a writing specialist) reminds us: "The truth, though, is that writing is not a skill learned once and then repeated forever, like scales on a piano." Rather, "every act of communication is like a new musical piece," one that needs to be analyzed and practiced [1]. Finally, even though they believe they still fall short of the proficiency level expected of them when they graduate, our students are now at least more aware of, and, one hopes, more prepared to face this challenge.

\subsection{REFERENCES}

[1] Paretti, M.C., "Communication as professional practice: Designing assignments to develop Engineering professionals," ASEE Southeast Section Conference, The University of Tennessee at Chattanooga, April 3-5, 2005.

[2] Shoemaker, C.A., "Student confidence as a measure of learning in an undergraduate Principles of Horticultural Science course," HortTechnology, August 2010 , v. 20 n.4, pp. 683-688.

[3]CDIO, "3. Determining the appropriate levels of student proficiency for syllabus topics," 2008. Available www.cdio.org/files/syllabus_pt3.pdf. Accessed May 4, 2015.

[4] Briggs, S., "Why self-esteem hurts learning but selfconfidence does the opposite," informED, July 5, 2014. http://www.opencolleges.edu.au/informed/features/selfefficacy-and-learning/ Accessed May 3, 2015.

[5] Rhoulac, T.D. and P. Crenshaw, "Preparing Civil Engineering students to meet workplace writing expectations," $36^{\text {th }}$ ASEE/IEEE Frontiers in Education Conference, San Diego, Session M1H, October 28-31, 2005.

[6] Pan, J.M. and H.S. Timperley, "Feedback to writing, assessment for teaching and learning and student progress," Assessing Writing, v.15, n.2, 2010, pp. 68-85.

[7] Davis, M.T., "Assessing technical communication within engineering contexts: Tutorial," IEEE Trans. On Professional Communication, 2010, v.53. n.4, pp. 33-45. 
Proc. 2015 Canadian Engineering Education Association (CEEA15) Conf.

[8] Ford, J.D. and L.A. Riley, "Integrating communication and Engineering education: A look at curricula, courses, and support systems," Journal of Engineering Education, October, 2003, pp. 325-328. 